Emilio Bouza

Javier Cobo²

$\mathrm{M}^{\mathrm{a}}$ Jesús Rodríguez-

Hernánde $z^{3}$

Miguel Salavert ${ }^{4}$

Juan P Horcajada ${ }^{5}$

José Antonio Iribarren ${ }^{6}$

Engels $\mathrm{Obi}^{7}$

Virginia Lozano ${ }^{8}$

Stefano Maratia ${ }^{8}$

Maribel Cuesta ${ }^{9}$

Estefany Uría ${ }^{9}$

Enric Limón ${ }^{10}$

\section{Economic burden of recurrent Clostridioides difficile infection in adults admitted to Spanish hospitals. A multicentre retrospective observational study}

\author{
${ }^{1}$ Hospital General Universitario Gregorio Marañón, Madrid, Spain \\ ${ }^{2}$ Hospital Universitario Ramón y Cajal, Madrid, Spain \\ ${ }^{3}$ Hospital Virgen del Rocío, Sevilla, Spain \\ ${ }^{4}$ Hospital Universitario y Politécnico de La Fe, Valencia, Spain \\ ${ }^{5}$ Hospital del Mar-IMIM, Barcelona, Spain \\ ${ }^{6}$ Hospital Universitario Donostia, San Sebastián, Spain \\ ${ }^{7}$ Merck \& Co., Inc., Kenilworth, NJ, USA \\ ${ }^{8}$ Merck Sharp \&t Dohme. Madrid, Spain \\ ${ }^{9}$ Oblikue Consulting, S.L. Barcelona, Spain \\ ${ }^{10}$ VINCat Coordinator Center, Catalan Health Department, University of Barcelona, Barcelona, Spain.
}

\section{Article history}

Received: 17 November 2020; Revision Requested: 9 December 2020; Revision Received: 15 December 2020; Accepted: 7 January 2021; Published: 23 February 2021

\section{ABSTRACT}

Introduction. Clostridioides difficile infection (CDI) is associated with increased hospital stays and mortality and a high likelihood of rehospitalization, leading to increased health resource use and costs. The objective was to estimate the economic burden of recurrent CDI (rCDI).

Material and methods. Observational, retrospective study carried out in six hospitals. Adults aged $\geq 18$ years with $\geq 1$ confirmed diagnosis (primary or secondary) of rCDI between January 2010 and May 2018 were included. rCDI-related resource use included days of hospital stay (emergency room, ward, isolation and ICU), tests and treatments. For patients with primary diagnosis of $r C D I$, the complete hospital stay was attributed to $\mathrm{rCDI}$. When diagnosis of rCDI was secondary, hospital stay attributed to rCDI was estimated using 1:1 propensity score matching as the difference in hospital stay compared to controls. Controls were hospitalizations without CDI recorded in the Spanish National Hospital Discharge Database. The cost was calculated by multiplying the natural resource units by the unit cost. Costs (euros) were updated to 2019.

Results. We included 282 rCDI episodes (188 as primary diagnosis): $66.31 \%$ of patients were aged $\geq 65$ years and $57.80 \%$ were female. The mean hospital stay (SD) was 17.18 (23.27) days: $86.17 \%$ of rCDI episodes were isolated for a mean (SD) of 10.30 (9.97) days. The total mean cost (95\%-CI) per episode was $€ 10,877(9,499-12,777)$, of which the hospital stay accounted for $92.56 \%$.

Correspondence:

Virginia Lozano

Merck Sharp \& Dohme

Calle de Josefa Valcárcel, 38, 28027, Madrid

Phone: +34913210600

E-mail: virginia.lozano@merck.com
Conclusions. There is high cost and resource use associated with rCDI, highlighting the importance of preventing rCDI to the Spanish National Health System.

Keywords: Clostridioides difficile, recurrence, cost analysis.

Carga económica de la infección por Clostridioides difficile en pacientes adultos tratados en hospitales españoles. Estudio observacional, retrospectivo, multicéntrico

Introducción. La infección por Clostridioides difficile (ICD) está asociada a un aumento de la estancia hospitalaria y de la mortalidad y a una alta probabilidad de reingreso, lo que conlleva un aumento de uso de recursos sanitarios y por tanto un incremento de costes. El objetivo del estudio fue estimar la carga económica de la ICD recurrente (ICDr).

Material y métodos. Estudio observacional, retrospectivo y multicéntrico. Se incluyeron pacientes adultos ( $\geq 18$ años), que tuvieran registrado al menos un episodio diagnóstico confirmado (primario o secundario) de ICDr durante enero 2010 y mayo 2018. El uso de recursos relacionado con la ICDr incluyó la estancia hospitalaria (urgencias previas, planta, aislamiento y UCI), así como pruebas y tratamientos. Para episodios que ingresaron por ICDr (diagnóstico principal) se consideró la estancia completa registrada. Cuando la ICDr se registró como diagnóstico secundario se estimó la estancia hospitalaria debida a ICDr mediante emparejamiento (1:1) utilizando la técnica "propensity score". Se consideraron como controles (episodios sin ICD) las hospitalizaciones registradas en Conjunto Mínimo Básico de las Altas Hospitalarias. El coste total se calculó multiplicando las unidades naturales de los recursos por el coste unitario correspondiente. Todos los costes fueron actualizados a euros de 2019. 
Resultados. Se incluyeron 282 episodios ICDr (188 como diagnóstico principal): $66,31 \%$ de los pacientes tenían más de 65 años y 57,80\% eran mujeres. La estancia media (DE) hospitalaria fue de $17,18(23,27)$ días. Un $86,17 \%$ de los episodios fueron aislados debido a ICDr con una media (DE) de 10,30 $(9,97)$ dias. El coste medio (IC-95\%) total por episodio fue de 10.877€ (9.499-12.777), siendo la duración de la estancia hospitalaria el $92,56 \%$ del coste total.

Conclusiones. Tanto el uso de recursos como el coste debido a la ICDr tienen un alto impacto para el sistema nacional de salud lo que pone de relieve la importancia de prevenir las ICDr.

Palabras clave: Clostridioides difficile, recurrencia, análisis de costes.

\section{INTRODUCTION}

Clostridioides difficile infections (CDI) range from uncomplicated diarrhoea and pseudomembranous colitis to fulminant colitis, resulting in sepsis and death in 2-3\% of patients [1-5]. Cytotoxins produced by C. difficile (toxin A, toxin B), which may inflame the colon and damage the surface of the epithelial mucosa [6] are responsible for most cases of antibiotic-associated pseudomembranous colitis [1-4] and 15-25\% of antibiotic-associated diarrhoeas [1].

In Spain, CDI is the most common nosocomial infection of the digestive system [7] and the most common cause of diarrhoea in hospitalized patients $[8,9]$. In recent decades there has been an increase in cases of diarrhoea associated with CDI, probably due to increased clinical suspicion and greater diagnostic sensitivity. According to the VINCat register (a Catalan Health Service programme that established a unified surveillance system for nosocomial Infections in Catalan hospitals), the incidence rate increased from 2.20 cases/10,000 hospital stays in 2011 to 3.41 in 2016 [10]. The increase was significant for all types of CDI: nosocomial, health care-related and community-acquired [11]. In Spain, the rate of hospitalizations due to CDI has increased from 3.9 cases per 100,000 persons in 2003 to 12.97 in 2013-15 [12]. The incidence may be up to 2.5 times higher in patients aged $\geq 65$ years [9]. The increased frequency of CDI correlates with increased antibiotic use, prolonged hospital stays and older age $[13,14]$.

Despite the progressive increase in the incidence of CDI, it remains an underdiagnosed pathology, a European study found that only 52\% of hospitals used an optimal algorithm for the diagnosis of CDI [15]. In Spain, Alcalá et al., found that $66.6 \%$ of patients infected with C. difficile are not well diagnosed [16], although this may have improved in recent years due to molecular diagnostic techniques.

The treatment of CDI is based on the administration of antibiotics, the application of preventive measures to control the infection, hydration and the avoidance of opiates and drugs that inhibit intestinal peristalsis. Approximately $85 \%$ of patients diagnosed respond to treatment. However, in 10-35\% of patients, despite treatment and the resolution of symptoms, CDI recurs within 8 weeks of the first episode [1, 17-19]. Anti- biotic use after the diagnosis of $\mathrm{CDI}$, the use of antacid agents, older age [17, 20-23], the persistence of spores, loss of diversity of the gut microbiota $[4,24-26]$ and previous episodes of CDI [27], severe CDI episodes, an insufficient immune response and the persistence of diarrhoea $>5$ days [14], are the main risk factors for $r C D I$. The first recurrence increases the percentage of new recurrences by up to 50-60\% [28-30]. Recurrence is one of the main complications of CDI because, in addition to increasing the risk of more recurrences, it worsens health outcomes $[4,23]$, including increased morbidity and mortality [31-33], leading to increased health resource use and, therefore, increased health costs. The cost of an inpatient with CDI is increased by 33\% to 54\% compared with the cost of a patient without CDI [34].

Few Spanish studies have analysed the economic impact of CDI. Asensio et al., estimated the annual expenditure for the Spanish National Health System (NHS) as $€ 32,157,093$. The high costs were mainly due to the prolonged length of hospital stay. The cost per episode of $C$. difficile-associated diarrhoea was $€ 3,901$ (initial infection), $€ 4,875$ (first recurrence) and $€$ 5,916 (second recurrence) [35]. Other analyses estimated that the cost attributable to CDI varied from $€ 3,750$ to $€ 4,396$ / patient, depending on the severity of the episodes $[12,36]$.

Given the lack of observational studies to estimate the burden of rCDI in Spanish patients in both resource use and costs, this study analysed the economic impact of $r C D I$ in real clinical practice.

\section{MATERIAL AND METHODS}

Design and study population. A descriptive, retrospective, multicentre observational study was conducted to estimate the economic burden of hospitalized episodes of rCDI. The study was carried out under conditions of usual clinical practice in six hospitals representative of the Spanish geography. The study was classified by the Spanish Agency for Medicines and Health Products as a non-post-authorization observational study and was approved by the Clinical Research Ethics Committee of the Hospital General Universitario Gregorio Marañón (study code: MSD-CDI-2016-01).

Researchers consecutively identified all the most recent episodes of rCDI that met the selection criteria within the inclusion period and these were collected in the electronic case report form (eCRF) designed for the study, the patient's sociodemographic and clinical data, as well as the episodes of rCDI associated with each patient and their use of resources. The unit of analysis was $\mathrm{rCDI}$ episodes. The economic assessment was conducted from the NHS perspective and the inclusion period was January 2010 to May 2018.

The study population included patients aged $\geq 18$ years of both sexes with $\geq 1$ confirmed diagnostic episode of rCDI during the inclusion period. Patients in whom it was not possible to obtain clinical and/or resource use data and those with episodes of rCDI, but who did not meet the study definition of rCDI were excluded. 
Data collection. We collected sociodemographic characteristics such as age and sex, the characteristics of hospitalization (type of admission, hospitalization service, primary diagnosis, secondary diagnoses and discharge destination), characteristics of each rCDI episode, including the number of recurrences, episode severity, the Charlson Comorbidity Index (CCI) and McCabe-Jackson index, if the patient was immunocompromised, antibiotic use and the use of proton pump inhibitors in the 30 days prior to diagnosis of rCDI. Diagnoses were recorded using the coding of the Spanish version of the International Classification of Diseases, Clinical Modification ninth revision (CIE-9-MC).

The use of rCDI-related resources included the hospital stay, testing, treatments (pharmacological and/or faecal microbiota transplant (FMT)) and surgical intervention due to rCDI.

\section{Definitions.}

- CDI diagnosis. A diagnosed CDI episode was defined using two criteria: a) diarrhoea, defined as $\geq 3$ evacuations of unformed faeces within 24 consecutive hours or less; $b$ ) a positive stool test for toxigenic $C$. difficile or its toxins $[25,37]$.

- rCDI. According to the European Society of Clinical Microbiology and Infectious Diseases [37] a recurrence was defined as a new episode of CDI within 8 weeks of the resolution of signs and symptoms of the previous episode.

Due to the difficulty in clinical practice of distinguishing between recurrences due to a recurrence of the infection by the original strain or a re-infection of patients who remained susceptible and were exposed to new strains [1], both mechanisms were considered as a recurrent episode.

Episodes that occurred during the first two days after the end of treatment for $\mathrm{CDI}$ or $\mathrm{rCDI}$ were considered therapeutic failures, and all resource consumption identified during that period was considered as resource use corresponding to that episode (Figure 1).

- Hospital stay. In the case of CDI as a primary diagnosis, the days spent in the emergency room prior to the ward stay and the ward stay recorded in the eCRF were attributed to recurrence.

In the case of CDI as a secondary diagnosis, the days spent in the emergency room prior to the ward stay and the ward stay attributed to recurrence were considered to be the difference in days of stay for the patient compared to a control patient without CDI (control group). Cases and controls were matched using the propensity score.

The days of isolation room and the days in the ICU recorded in the eCRF were attributed to the recurrence in all episodes.

- Spanish National Hospital Discharge Database (SNHDD) - Controls. Hospital discharges registered with the minimum basic data set (SNHDD) of the Ministry of Health, Consumer Health and Social Welfare were included as controls. The SNHDD gathers information on patient characteristics (age and sex), hospitalization (type of admission and discharge, and hospital stay), diagnoses and some relevant therapeutic interventions, especially surgical interventions, used to treat the patient during hospitalization (procedures). Diagnoses and procedures were recorded using the CIE-9-MC coding. The SNHDD register is mandatory and includes all acute hospital discharges from the NHS [38]. The CCl calculation [39] was adapted for use with an administrative database [40].

Costs. Direct health costs were included to estimate the economic impact of rCDI on adult patients in Spain from the NHS perspective.

The unit costs of resource use were obtained from the ESALUD database [41] and drug treatments from the website of the General Council of Official Colleges of Pharmacists (Bot PLUS) [42]. All costs were updated to 2019 euros.

Direct health costs included resource use during hospitalization due to $\mathrm{rCDI}$ (previous emergency room admissions, ward, isolation room, and ICU stays; testing and treatment). The costs of tests were calculated by multiplying the natural units of the resources used by the associated unit cost. The

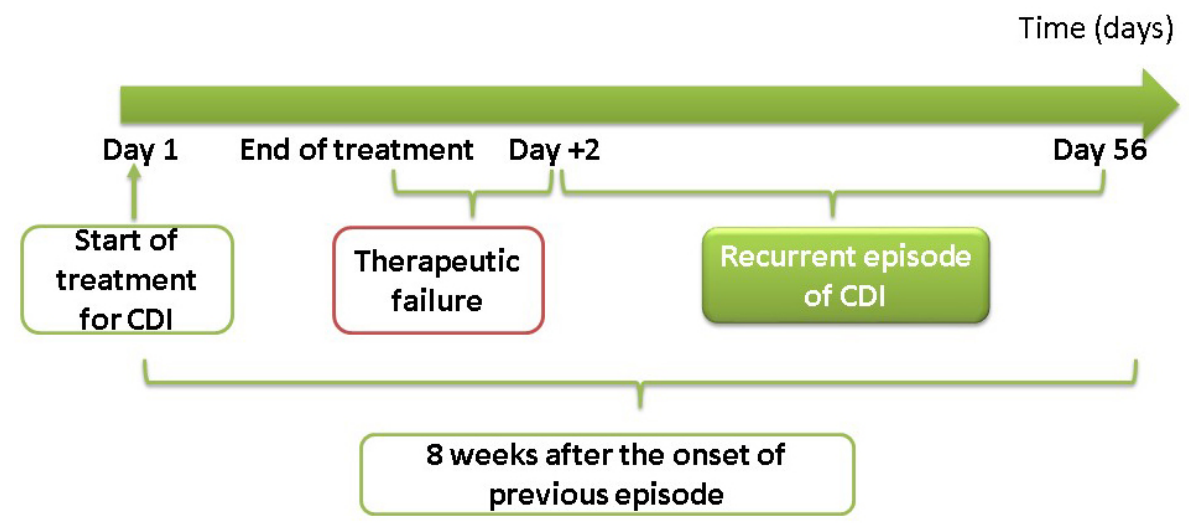

\begin{tabular}{l|l} 
Figure 1 & Definition of an rCDI episode
\end{tabular} 
cost of the hospital stay (ward, isolation room, ICU) was obtained by multiplying the days of stay by the corresponding unit cost.

The total dose was calculated for each active substance used during hospitalization by multiplying the dose by the length of treatment. The cost of each treatment was obtained by multiplying the total dose that each patient received during hospitalization by the unit cost of each treatment. The wholesale price without Value Added Tax was applied according to the presentation of the medicine.

Stratifications. Stratified analyses were made to estimate the cost of $r C D I$ according to age ( $\leq 65$ years, $>65$ years), sex, severity of the episode (mild or moderate, severe, severe-complicated), immunosuppressive status and number of recurrences $(1,2, \geq 3)$.

Statistical analysis. A descriptive analysis was made of the study variables. Quantitative variables were described using means and standard deviation (SD) and qualitative variables using absolute and relative frequencies. Confidence intervals $(\mathrm{Cl})$ were calculated using bootstrapping techniques employing replacement samples of the same size as the original sample $[43,44]: 10,000$ simulations were made and the 2.5th and 97.5th percentiles of the distribution were used to determine the $95 \% \mathrm{Cl}$.

rCDI episodes and the control group were matched (1:1) using the propensity score employing the greedy matching algorithm. l.e., once a control episode was selected, that control was not reconsidered [45]. A logistic regression model adjusting for covariates was developed to estimate propensity to develop CDI among patients in the case and control cohorts. The covariates included were sex and age, comorbidities during hospitalization, type of admission and discharge and primary diagnosis. Each propensity score included the hospital admission date for cases and controls to ensure the length of hospital stay before the event was similar in the two groups and was not a confounding factor.

The matching of the two groups was restricted by the primary diagnosis. In the event of more than one control being available for the case, selection was carried out randomly. The analysis was performed only in matched episodes. Episodes of rCDI without a comparable control were excluded from the study. Differences in characteristics between rCDI episodes and controls were evaluated using standardized differences [46]

Sensitivity analysis. To validate the analysis, a sensitivity analysis of the matching technique was made. Secondary diagnoses were considered in this analysis in addition to the covariates included in the main analysis (sex and age, comorbidities during hospitalization, type of admission and discharge, and primary diagnosis): i.e., the case and control coincided in as many secondary diagnoses as was possible.

The analysis was conducted using the $\mathrm{R}$ statistical package (version 3.6.1) [47].

\section{RESULTS}

The initial cohort included 230 hospitalized patients with rCDI, of whom 224 patients with 290 recorded rCDI episodes were valid for the analysis. Of these 290 recurrent episodes, 188 had a primary diagnosis of CDI and 102 a secondary diagnosis of CDI. These 102 episodes were matched with episodes without CDI using propensity scores: controls were found for 94 episodes and 8 episodes were excluded from the analysis. The standardized differences in baseline characteristics for comparisons of the two groups were $<0.2$ (small effect), suggesting that pro-

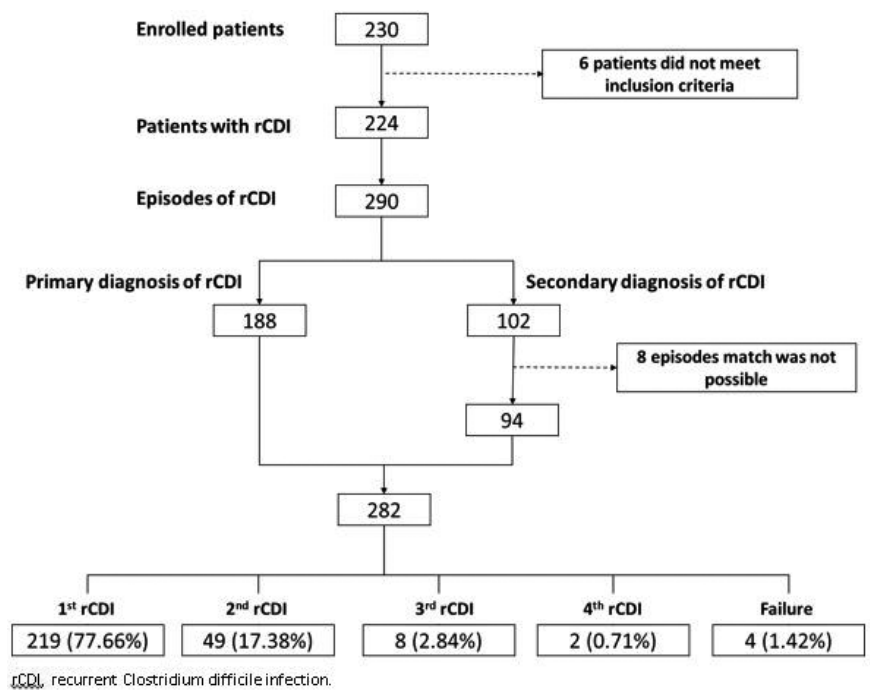

\begin{tabular}{l|l} 
Figure 2 & Flow chart of rCDI episodes
\end{tabular} 


\begin{tabular}{|c|c|c|c|}
\hline \multirow[t]{2}{*}{ Table 1} & \multicolumn{3}{|c|}{$\begin{array}{l}\text { Sociodemographic data, and clinical } \\
\text { and hospitalization characteristics due } \\
\text { to rCDI }\end{array}$} \\
\hline & & rCDI & N \\
\hline \multicolumn{4}{|c|}{ Sociodemographic features } \\
\hline \multicolumn{2}{|c|}{ Age [years] - Mean (SD) } & $70.71(18.16)$ & 282 \\
\hline \multicolumn{2}{|c|}{ Female - n (\%) } & $163(57.80 \%)$ & 282 \\
\hline \multicolumn{4}{|c|}{ Clinical characteristics } \\
\hline \multicolumn{2}{|c|}{ Episode severity - n (\%) } & & 282 \\
\hline \multicolumn{2}{|c|}{ Mild or moderate } & $168(59.57 \%)$ & \\
\hline \multicolumn{2}{|l|}{ Severe } & $92(32.62 \%)$ & \\
\hline \multicolumn{2}{|c|}{ Severe-complicated } & $22(7.80 \%)$ & \\
\hline \multicolumn{2}{|c|}{ Comorbidities $^{\mathrm{b}, \mathrm{c}}-\mathrm{n}(\%)$} & & 282 \\
\hline \multicolumn{2}{|c|}{ Chronic kidney failure } & $100(35.46 \%)$ & \\
\hline \multicolumn{2}{|c|}{ Heart failure } & $68(24.11 \%)$ & \\
\hline \multicolumn{2}{|c|}{ Chronic respiratory disease } & $57(20.21 \%)$ & \\
\hline \multicolumn{2}{|c|}{ Tumour or solid neoplasm without metastasis } & $46(16.31 \%)$ & \\
\hline \multicolumn{2}{|c|}{ Diabetes with target organ injury } & $44(15.60 \%)$ & \\
\hline \multicolumn{2}{|c|}{ Cerebrovascular disease } & $41(14.54 \%)$ & \\
\hline \multicolumn{2}{|c|}{ Diabetes without target organ injury } & $39(13.83 \%)$ & \\
\hline \multicolumn{2}{|c|}{ Peripheral artery disease } & $34(12.06 \%)$ & \\
\hline \multicolumn{2}{|c|}{ Moderate-severe chronic liver disease } & $32(11.35 \%)$ & \\
\hline \multicolumn{2}{|l|}{ Dementia } & $29(10.28 \%)$ & \\
\hline \multicolumn{2}{|l|}{ Other } & $104(36.88 \%)$ & \\
\hline \multicolumn{2}{|c|}{ Charlson index score $-\mathrm{n}(\%)$} & & 282 \\
\hline \multicolumn{2}{|l|}{$<3$ points } & $33(11.70 \%)$ & \\
\hline \multicolumn{2}{|l|}{$\geq 3$ points } & $249(88.33 \%)$ & \\
\hline \multicolumn{2}{|c|}{ McCabe-Jackson index - n (\%) } & & 282 \\
\hline \multicolumn{2}{|c|}{ I (Rapidly fatal) } & $14(4.96 \%)$ & \\
\hline \multicolumn{2}{|c|}{ II (Ultimately fatal) } & $118(41.84 \%)$ & \\
\hline \multicolumn{2}{|c|}{ III (Non-fatal) } & $150(53.19 \%)$ & \\
\hline \multicolumn{2}{|c|}{ Immunocompromised patient - $\mathrm{n}(\%)$} & $88(31.21 \%)$ & 282 \\
\hline \multicolumn{2}{|c|}{ Previous use of antibiotics ${ }^{d}-n(\%)$} & $221(81.55 \%)$ & 271 \\
\hline Previous use $\mathrm{c}$ & n pump inhibitors ${ }^{\mathrm{d}}-\mathrm{n}(\%)$ & $230(82.44 \%)$ & 279 \\
\hline
\end{tabular}

pensity score matching was effective in minimizing the baseline differences (Supplementary table A-1). Finally, 282 episodes of rCDI (corresponding to 217 patients) were analysed, of which 77.66\% were a first recurrence (Figure 2).

The mean age was 71 years (SD: 18.16), 57.80\% of patients were female, and $60 \%$ of episodes were mild or moderate in severity. In $88.33 \%$ of episodes, patients had high comorbidity ( $\mathrm{CCl} \geq 3$ points). The most common comorbidities were chronic kidney failure (35.46\%), heart failure (24.11\%) and chronic respiratory disease (20.21\%). In $31.21 \%$ of episodes patients

\begin{tabular}{|c|c|c|c|}
\hline \multirow[t]{2}{*}{ Table 1} & \multicolumn{3}{|c|}{$\begin{array}{l}\text { Sociodemographic data, and clinical } \\
\text { and hospitalization characteristics due } \\
\text { to rCDI (cont.) }\end{array}$} \\
\hline & & $\mathrm{rCDI}$ & $\mathrm{N}$ \\
\hline \multicolumn{4}{|c|}{ Characteristics of hospitalization } \\
\hline \multicolumn{2}{|c|}{ Type of admission - $n(\%)$} & & 282 \\
\hline \multicolumn{2}{|l|}{ Urgent } & $267(94.68 \%)$ & \\
\hline \multicolumn{2}{|c|}{ Programmed } & $15(5.32 \%)$ & \\
\hline \multicolumn{3}{|c|}{ Type of hospitalization service discharge $-\mathrm{n}(\%)$} & 282 \\
\hline \multicolumn{2}{|l|}{ Medical } & $259(91.84 \%)$ & \\
\hline \multicolumn{2}{|l|}{ Surgical } & $16(5.67 \%)$ & \\
\hline \multicolumn{2}{|c|}{ Other service } & $7(2.48 \%)$ & \\
\hline \multicolumn{2}{|c|}{ Discharge destination - $\mathrm{n}(\%)$} & & 282 \\
\hline \multicolumn{2}{|l|}{ Home } & $180(63.83 \%)$ & \\
\hline \multicolumn{2}{|c|}{ Transfer to social health centre } & $41(14.54 \%)$ & \\
\hline \multicolumn{2}{|c|}{ Hospital deaths } & $35(12.41 \%)$ & \\
\hline \multicolumn{2}{|l|}{ Other } & $17(6.03 \%)$ & \\
\hline \multicolumn{2}{|c|}{ Transfer to another hospital } & $8(2.84 \%)$ & \\
\hline \multicolumn{2}{|c|}{ Voluntary discharge } & $1(0.35 \%)$ & \\
\hline
\end{tabular}

${ }^{\mathrm{a}} \mathrm{Age}$ at the time of assignment of ward bed. ${ }^{\mathrm{b}}$ Mutually non-exclusive categories. '0thers: leukaemia $(n=18)$; myocardial infarction $(n=18)$; lymphoma $(n=$ 17); tumour or solid neoplasm with metastasis $(n=16)$; gastroduodenal ulcer (peptic) ( $n=12)$; connective tissue disease $(n=7)$; mild chronic liver disease $(n=7)$; hemiplegia $(n=5)$; AIDS $(n=4)$. dDuring the 30 days prior to the diagnosis of rCDI episode. 'Medical service: Digestive, cardiology, dermatology, endocrinology, infectious diseases, neurology, geriatrics, haematology, internal medicine, nephrology, pneumology, medical oncology, paediatrics, rehabilitation, rheumatology, internal medicine. Surgical service: Angiology and vascular surgery, cardiac surgery, general and digestive surgery, maxillofacial surgery, chest surgery, gynaecology, neurosurgery, urology, obstetrics, ophthalmology, otolaryngology, trauma and orthopaedic surgery.

rCDI, recurrent Clostridioides difficile infection; SD, standard deviation; IQR interquartile range.

were immunocompromised, $81.55 \%$ and $82.44 \%$ used antibiotics (any reason) and proton pump inhibitors, respectively, during the 30 days before the diagnosis of rCDI. In 63.83\% of episodes, the discharge destination was home, and there were 12.41\% hospital deaths (Table 1).

Resource use. The total mean hospital stay (SD) due to rCDI, including the days of stay in the emergency room prior to the hospitalization, was 17.18 (23.27) days. In 86.17\% of episodes, an isolation room due to rCDI was required, with a mean stay (SD) of 10.30 (9.97) days. The most common tests 


\begin{tabular}{|c|c|c|c|c|}
\hline \multirow[t]{2}{*}{ Table 2} & \multicolumn{4}{|c|}{ Resource use and total cost per episode of rCDI. } \\
\hline & & Episodes $(\%)$ & Mean resource use (SD) & $\begin{array}{c}\text { Total cost }(€) \\
\text { Mean }(95 \% \text { Cl) }\end{array}$ \\
\hline \multicolumn{5}{|c|}{ HOSPITAL STAY DUE TO rCDI [days] ${ }^{\text {a }}$} \\
\hline \multicolumn{2}{|c|}{ Emergency room before assignation of ward bed } & $15.60 \%$ & $1.48(0.63)$ & \\
\hline \multicolumn{2}{|c|}{ Isolation room } & $86.17 \%$ & $10.30(9.97)$ & \\
\hline \multicolumn{2}{|c|}{ Ward stay } & $62.77 \%$ & $12.12(23.72)$ & \\
\hline \multicolumn{2}{|l|}{ ICU } & $2.84 \%$ & $16.50(18.34)$ & \\
\hline \multicolumn{2}{|l|}{ Total } & $100.00 \%$ & $17.18(23.27)$ & $10,068(8,717-11,920)$ \\
\hline \multicolumn{5}{|c|}{ TESTS DUE TO rCDI [n] a } \\
\hline \multicolumn{2}{|c|}{ Biochemistry } & $35.82 \%$ & $2.95(2.62)$ & \\
\hline \multicolumn{2}{|c|}{ Diagnostic imaging } & $28.37 \%$ & $1.25(0.56)$ & \\
\hline \multicolumn{2}{|c|}{ Cultures } & $22.34 \%$ & $2.75(0.62)$ & \\
\hline \multicolumn{2}{|c|}{ Colonoscopies } & $6.03 \%$ & $1.00(0.00)$ & \\
\hline \multicolumn{2}{|c|}{ Other tests } & $7.09 \%$ & $1.15(0.49)$ & \\
\hline \multicolumn{2}{|l|}{ Total } & $100.00 \%$ & & $155(134-181)$ \\
\hline \multicolumn{5}{|c|}{ TREATMENT DUE TO rCDI ${ }^{a, b, c}$} \\
\hline \multicolumn{2}{|c|}{ Vancomycin [mg] } & $65.48 \%$ & $621.31(522.82)$ & \\
\hline \multicolumn{2}{|c|}{ Metronidazole [mg] } & $50.89 \%$ & $1,480.54(195.96)$ & \\
\hline \multicolumn{2}{|c|}{ Fidaxomicin $[\mathrm{mg}]$} & $26.69 \%$ & 397.40 (22.79) & \\
\hline \multicolumn{2}{|c|}{ Faecal microbiota transplant [n] } & $4.27 \%$ & na & \\
\hline \multicolumn{2}{|c|}{ Rifaximin [mg] } & $1.42 \%$ & $800.00(0.00)$ & \\
\hline \multicolumn{2}{|c|}{ Tigecycline $[\mathrm{mg}]$} & $0.36 \%$ & 100.00 (na) & \\
\hline \multicolumn{2}{|c|}{ Non-specific immunoglobulin [mg] } & $0.36 \%$ & $2,500.00$ (na) & \\
\hline \multicolumn{2}{|l|}{ Total } & $99.65 \%$ & & $484(403-580)$ \\
\hline \multicolumn{5}{|c|}{ OTHER RESOURCE USE DUE TO rCDI [n] } \\
\hline \multicolumn{2}{|l|}{ Surgery } & $0.35 \%$ & 1 (na) & \\
\hline \multicolumn{2}{|l|}{ Total } & & & $24.69(0-74.07)$ \\
\hline \multicolumn{2}{|c|}{ Therapeutic failure } & $1.42 \%$ & na & \\
\hline \multicolumn{2}{|l|}{ Total } & & & $145(32.38-411)$ \\
\hline \multicolumn{3}{|c|}{ TOTAL COST PER rCDI EPISODE } & & $10,877(9,499-12,777)$ \\
\hline
\end{tabular}

rCDI, recurrent Clostridioides difficile infection; SD, standard deviation; $\mathrm{Cl}$, confidence interval; na, not applicable.

${ }^{a}$ Mutually non-exclusive resources. ${ }^{b}$ One episode received no treatment for $\mathrm{rCDI}$. ${ }^{\mathrm{P} P e r c e n t a g e}$ of episodes calculated from episodes that received treatment.

for $r$ rDI were biochemistry (35.82\%), imaging (28.37\%) and cultures (22.34\%), with a mean (SD) of 2.95 (2.62); $1.25(0.56)$; and 2.75 (0.62) tests per episode, respectively. All other recorded tests were made in less than 7\% of episodes (Table 2).

The most common pharmacological treatments prescribed for rCDI were vancomycin (65.48\%), metronidazole (50.89\%) and fidaxomicin (26.69\%). All other drugs were prescribed in $<2 \%$ of episodes. One episode received no treatment for CDI. FMT was carried out in $4.27 \%$ of episodes (Table 2).

Costs. The mean total cost $(95 \% \mathrm{Cl})$ per episode was
$€ 10,877$ (9,499-12,777): $92.56 \%$ of the total cost was due to the length of the hospital stay, while the remaining $7.44 \%$ was distributed between treatments (4.45\%), testing $(1.43 \%)$, therapeutic failure $(1.33 \%)$ and surgery $(0.23 \%)$ (Table 2).

The hospital stay was the greatest contributor to the total cost (mean [95\% CI]: $€ 10,068[8,717-11,920]$ ), of which $51.05 \%$ was due to the need for an isolation room, $37.30 \%$ to the ward stay, $7.10 \%$ to the ICU stay, and $4.55 \%$ to pre-hospitalization emergency room stays. 


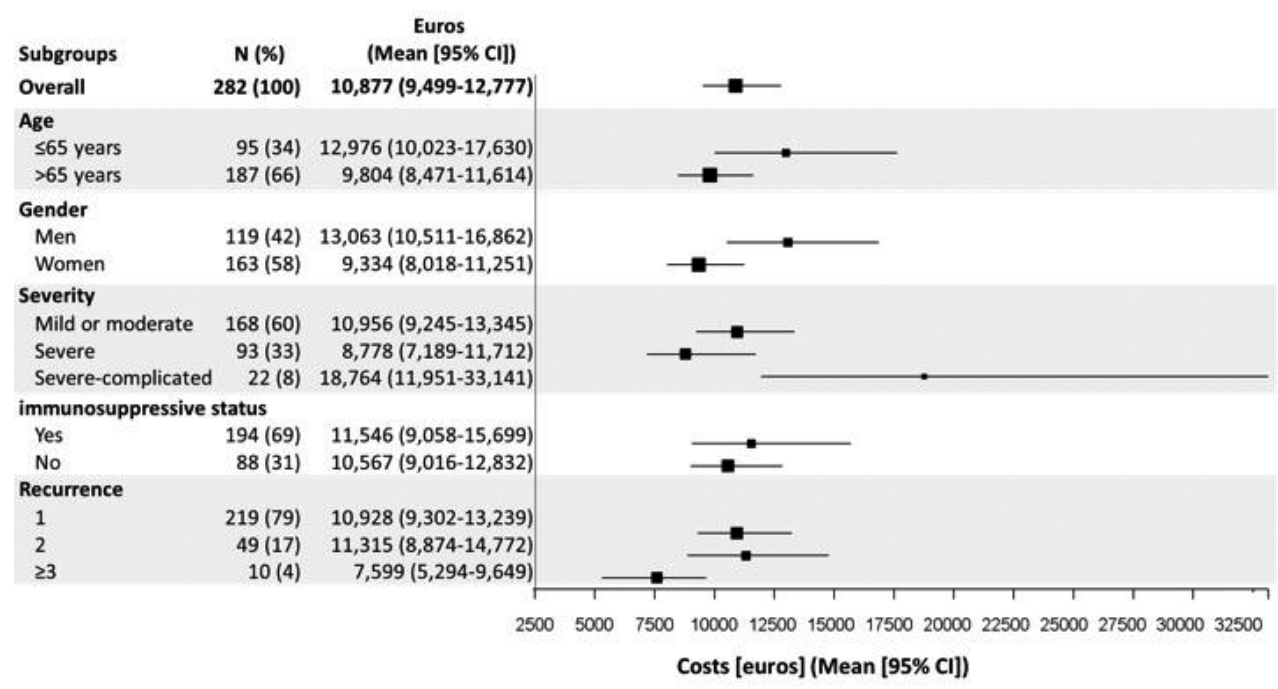

Figure $3 \quad$ Total cost per episode of rCDI stratified according to age, sex, severity, immunosuppression and severity

Figure 3 shows the total cost, stratified by subgroups. The total mean cost per rCDI episode was higher in patients aged $\leq 65$ years ( $€ 12,976$ vs. $€ 9,804$, in patients aged $\leq 65$ years and $>65$ years, respectively), in men (€13,063 vs. €9,334, in men vs women, respectively), and in immunosuppressed patients (€11,545 vs. €10,567, in immunosuppressed and non-immunosuppressed patients, respectively). These results should be interpreted with caution due to the small sample size in some subgroups.

Sensitivity analysis. We included the 188 episodes with a primary diagnosis. Of the 102 episodes with a secondary diagnosis of CDI, 66 episodes were matched with controls fulfilling the established criteria. Therefore, 254 episodes (188 rCDI episodes as the primary diagnosis) were analysed. Both the total mean stay (SD) and the mean cost (SD) due to rCDI was very similar to the main analysis, resulting in 17.53 (23.84) days of hospital stay and €11.151 (9.649 - 13.244) per rCDI episode.

\section{DISCUSSION}

This study assessed the economic impact and burden of hospitalizations due to rCDI in real clinical practice in Spain. Unlike other studies, we took into account the cost of the pre-hospitalization emergency room stay and the cost of patient isolation due to infection. In addition, episodes of rCDI recorded as both primary and secondary diagnoses were included. Therefore, we were able to estimate the resource use and cost of $\mathrm{rCDI}$ episodes that require hospital management in real clinical practice.

Our results showed a mean hospital stay of 17.18 days per rCDI episode. Studies have shown that the mean stay in Spain ranges from 9.1 to 45.0 days per recurrent episode $[35,36]$, while in Europe it ranges from 20.1 to 33 days [36, 48, 49]. In general, while there are wide variations in the length of hospital stay, most studies agree that rCDI has a longer hospital stay than initial episodes of CDI. Wilcox et al. [50] observed a median hospital stay of 15.5 days for initial episodes and 21 days for recurring episodes, while Tresman and Goldenberg [49] found a mean stay of 17 and 33 days, for initial and recurring episodes, respectively.

The mean cost per rCDI episode in our study was $€ 10,877$, of which approximately $93 \%$ corresponded to the hospital stay (€ 10,068). The costs found are clearly higher than those obtained in previous reports on the cost of rCDI in Spain. Asensio et al. [35] found a mean cost per CDI episode of $€ 4,875$ and $€ 5,916$ for the first and second recurrences, respectively, half the estimated costs found in our study. One of the main reasons for this difference may be the study design: we used a retrospective, multicentre observational design in real clinical practice, while Asensio et al. used the Delphi method, with a panel of three experts estimating the cost per episode. Although the Delphi method has proven useful in reaching consensus in areas of uncertainty or when empirical evidence is lacking, the results stem from the opinions and perceptions of experts. Our results are in line with similar European studies that found the cost of an episode of $r C D I$ ranges from $€ 7,539$ to $€ 31,121[36,48-50]$. We observed that isolation rooms accounted for $47 \%$ of the total cost, results similar to those of other European studies, where isolation rooms contributed between $26 \%$ and $46 \%$ of the total cost of the episode [51, 52]. Despite its high contribution to the total cost, an isolation room of patients with symptoms of CDI is one of the key infection control measures [25].

The incidence rate of CDI in Spain has increased from 2.20 cases/10,000 patients in 2011 to 3.41 in 2016 [10]. C. dif- 
ficile infections have a high rate of recurrence after the end of treatment, which may complicate the prognosis due to increased morbidity and mortality. In recent decades, in Europe the recurrence rate has increased to 35\% [37] while, in Spain, descriptive studies have reported a recurrence rate of 12-18\% $[6,13,23]$. The risk of recurrence increases after each new episode, increasing morbidity, health resource use and 90-day mortality [53], as shown by the stratification of the cost per episode of the first recurrence $(€ 10,928)$ and the second recurrence $(€ 11,315)$ in our study, although these results should be interpreted with caution due to the small sample size in some subgroups.

Some limitations of the study may have influenced the results. First, the methodology used to estimate additional days due to $r C D I$ in episodes with rCDI recorded as a secondary diagnosis. Matching using the propensity score was successful in adjusting the imbalances observed between the two cohorts (rCDI episodes and episodes without CDI). However, this methodology cannot correct possible imbalances between the two cohorts due to potentially important unobserved characteristics.

Secondly, the use of the SNHDD administrative database to search for episodes without CDI (controls), means results were conditioned on the quality of the data record in the discharge reports. In addition, although this database is very useful in hospital management, it does not record potentially important information such as resource use during hospitalization (tests, treatments) or patient characteristics (weight, comorbidity, clinical characteristics).

Thirdly, the impact of $r C D I$ could be underestimated because we analysed only hospitalized rCDI episodes and therefore the resource use due to a recurring episode after hospital discharge (if any) was not considered, nor were episodes that were moved to another hospital or long-stay centre considered. Neither was the cost of infection control measures, such as disposable gloves, gowns and thermometers or room cleaning after patient discharge considered.

In conclusion, until now, no Spanish study has been specifically designed to assess the impact of the hospital management of rCDI in real clinical practice. Therefore, our results may represent the first contribution on this topic available in Spain. Despite the limitations of the study, the results show that the recurrence of $\mathrm{CDI}$ represents a significant burden on the NHS, highlighting the importance of preventing CDI recurrences.

\section{FUNDING}

This work was supported by Merck Sharp \& Dohme

\section{CONFLICTS OF INTEREST}

$E B$, has participated in clinical trials and advisory boards sponsored by MSD, Pfizer and Astellas. JC received fees as a speaker in conferences and advisory board meetings from Astellas and MSD. MJR-H received fees as a speaker and partici- pant in advisory board meetings from Astellas and MSD. MS has lectured at meetings organized by pharmaceutical companies (MSD, Janssen, Pfizer and Gilead) or participated in some medical advice. He has not received direct grants or scholarships. JPH has received fees as a speaker and participant in advisory board meetings from Pfizer, MSD, Menarini and Zambon and a research grant from MSD. JAI reported no conflicts of interest. EO is an employee of Merck \& Co. VL is an employee of Merck Sharp \& Dohme. SM was an employee of Merck Sharp \& Dohme. $\mathrm{MC}$ and EU are employees of Oblikue Consulting. EL declares he has been a speaker in a symposium organized by MSD.

\section{REFERENCES}

1. Barbut $F$, Richard A, Hamadi $K_{1}$ et al. Epidemiology of Recurrences or Reinfections ofClostridium Epidemiology of Recurrences or Reinfections of Clostridium difficile-Associated Diarrhea. J Clin Microbiol 2000; 38: 2386-2388.

2. Sunenshine RH, McDonald LC. Clostridium difficile-associated disease: new challenges from an established pathogen. Cleve Clin J Med 2006; 73: 187-97. doi: 10.3949/ccjm.73.2.187.

3. Bartlett JG. Historical perspectives on studies of Clostridium difficile and C. difficile infection. Clin Infect Dis 2008; 46 Suppl 1: S4-11. doi: 10.1086/521865.

4. Freeman J, Bauer MP, Baines SD, et al. The changing epidemiology of Clostridium difficile infections. Clin Microbiol Rev 2010; 23: 529-49. doi: 10.1128/CMR.00082-09.

5. Monge D, Morosini M, Millán I, et al. [Risk factors for Clostridium difficile infections in hospitalized patients]. Med Clin (Barc) 2011; 137: 575-80. doi: 10.1016/j.medcli.2010.12.026.

6. Rodríguez-Pardo D, Almirante B, Bartolomé RM, et al. Epidemiology of Clostridium difficile infection and risk factors for unfavorable clinical outcomes: results of a hospital-based study in Barcelona, Spain. J Clin Microbiol 2013; 51: 1465-73. doi: 10.1128/ JCM.03352-12.

7. Sociedad Española de Medicina Preventiva Salud Pública e Higene. ESTUDIO EPINE-EPPS no 30: 2019 Informe España. 2019; 33-36. https://epine.es/api/documento-publico/2019\%20EPINE\%20Informe\%20Espa\%C3\%B1a\%2027112019.pdf/reports-esp

8. Asensio A, Vaque-Rafart J, Calbo-Torrecillas F, et al. Increasing rates in Clostridium difficile infection (CDI) among hospitalised patients, Spain 1999-2007. Euro Surveill 2008; 13: 13-16.

9. Soler $\mathrm{P}$, Nogareda $\mathrm{F}, \mathrm{Cano}$ R. Rates of Clostridium difficile infection in patients discharged from Spanish hospitals, 1997-2005. Infect Control Hosp Epidemiol 2008; 29: 887-9. doi: 10.1086/590392.

10. Sopena $N$, Freixas $N$, Bella $F$, et al. Impact of a training program on the surveillance of Clostridioides difficile infection. Epidemiol Infect 2019; 147:e231. doi: 10.1017/S0950268819001080.

11. Mateu L, Fernández-Rivas G, Sopena N. Diagnosis and treatment of Clostridioides difficile infection. Med Clin (Barc) 2020; 155: 30-35. doi: 10.1016/j.medcli.2020.02.005.

12. Esteban-Vasallo MD, de Miguel-Díez J, López-de-Andrés A, et al. Clostridium difficile-related hospitalizations and risk factors for 
in-hospital mortality in Spain between 2001 and 2015. J Hosp Infect 2019; 102: 148-156. doi: 10.1016/j.jhin.2018.09.006.

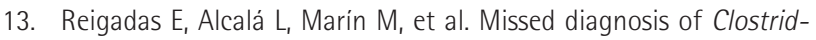
ium difficile infection; a prospective evaluation of unselected stool samples. J Infect 2015; 70: 264-272. doi: 10.1016/j. jinf.2014.10.013.

14. Bouza $E_{1}$ Aguado JM, Alcalá L, et al. Recommendations for the diagnosis and treatment of clostridioides difficile infection: An official clinical practice guideline of the spanish society of chemotherapy (SEQ), spanish society of internal medicine (SEMI) and the working group of postoperative. Rev Esp Quimioter 2020; 33: 151-175. doi: 10.37201/req/2065.2020.

15. Davies KA, Longshaw $\mathrm{CM}$, Davis $\mathrm{GL}$, et al. Underdiagnosis of Clostridium difficile across Europe: the European, multicentre, prospective, biannual, point-prevalence study of Clostridium difficile infection in hospitalised patients with diarrhoea (EUCLID). Lancet Infect Dis 2014; 14: 1208-19. doi: 10.1016/S14733099(14)70991-0.

16. Alcalá $L$, Martín $A$, Marin $M$, et al. The undiagnosed cases of Clostridium difficile infection in a whole nation: where is the problem? Clin Microbiol Infect 2012; 18(7): E204-13. doi: 10.1111/j.1469-0691.2012.03883.x.

17. Garey KW, Sethi $S$, Yadav $Y$, et al. Meta-analysis to assess risk factors for recurrent Clostridium difficile infection. J Hosp Infect 2008; 70: 298-304. doi: 10.1016/j.jhin.2008.08.012.

18. Pérez $\mathrm{M}_{1}$ Hurtado $\mathrm{Al}_{1}$ Couto I, et al. Abordaje multidisciplinario de la infección por Clostridium difficile. Rev Chil infectología 2013; 30: 165-185. doi: 10.4067/S0716-10182013000200008.

19. Salavert Lletí M. Choice of treatment in Clostridium difficile-associated diarrhoea: Clinical practice guidelines or risk classifications. Enferm Infecc Microbiol Clin 2017; 35: 613-616. doi: 10.1016/j. eimc.2017.11.004.

20. Pepin J, Alary M-E, Valiquette $L$, et al. Increasing risk of relapse after treatment of Clostridium difficile colitis in Quebec, Canada. Clin Infect Dis 2005; 40: 1591-7. doi: 10.1086/430315.

21. Kelly CP. Can we identify patients at high risk of recurrent Clostridium difficile infection? Clin Microbiol Infect 2012; 18 Suppl 6: 217. doi: 10.1111/1469-0691.12046.

22. Hebert $C_{1}$ Du $H_{1}$ Peterson $L R$, et al. Electronic health record-based detection of risk factors for Clostridium difficile infection relapse. Infect Control Hosp Epidemiol 2013; 34: 407-14. doi: 10.1086/669864.

23. Larrainzar-Coghen $T$, Rodriguez-Pardo $D$, Puig-Asensio $M$, et al. First recurrence of Clostridium difficile infection: clinical relevance, risk factors, and prognosis. Eur J Clin Microbiol Infect Dis 2016; 35: 371-378. doi: 10.1007/s10096-015-2549-9.

24. Voth DE, Ballard JD. Clostridium difficile toxins: mechanism of action and role in disease. Clin Microbiol Rev 2005; 18: 247-63. doi: 10.1128/CMR.18.2.247-263.2005

25. Cohen SH, Gerding DN, Johnson S, et al. Clinical practice guidelines for Clostridium difficile infection in adults: 2010 update by the society for healthcare epidemiology of America (SHEA) and the infectious diseases society of America (IDSA). Infect Control Hosp
Epidemiol 2010; 31: 431-55. doi: 10.1086/651706.

26. Cózar-Llistó A, Ramos-Martinez A, Cobo J. Clostridium difficile Infection in Special High-Risk Populations. Infect Dis Ther 2016; 5: 253-69. doi: 10.1007/s40121-016-0124-z.

27. Sebastian EC, Rodrigues GC, Sopena N, et al. Clinical outcomes in oncological patients with Clostridioides difficile infection in CataIonia: a cohort study [Abstract 7116]. In: 30th European Congress of Clinical Microbiology and Infectious Diseases (ECCMID). 2020.

28. Johnson S. Recurrent Clostridium difficile infection: a review of risk factors, treatments, and outcomes. J Infect 2009; 58: 403-10. doi: 10.1016/j.jinf.2009.03.010.

29. Verma P, Makharia GK. Clostridium difficile associated diarrhea: new rules for an old game. Trop Gastroenterol 2011; 32: 15-24.

30. Riddle D, Dubberke E. Clostridium difficile Infection in the Intensive Care Unit. Natl Inst Heal Public Access 2010; 23: 1-16. doi:10.1016/j.idc.2009.04.011.Clostridium.

31. Alcalá Hernández L, Reigadas Ramírez E, Bouza Santiago E. Clostridium difficile infection. Med Clin (Barc) 2017; 148: 456-463. doi: 10.1016/j.medcli.2017.01.033.

32. Olsen MA, Yan Y, Reske KA, et al. Recurrent Clostridium difficile infection is associated with increased mortality. Clin Microbiol Infect 2015; 21: 164-70. doi: 10.1016/j.cmi.2014.08.017.

33. Olsen MA, Yan Y, Reske KA, et al. Impact of Clostridium difficile recurrence on hospital readmissions. Am J Infect Control 2015; 43: 318-22. doi: 10.1016/j.ajic.2014.12.020.

34. Dubberke ER, Wertheimer Al. Review of current literature on the economic burden of Clostridium difficile infection. Infect Control Hosp Epidemiol 2009; 30: 57-66. doi: 10.1086/592981.

35. Asensio Á, Bouza E, Grau S, et al. [Cost of Clostridium difficile associated diarrhea in Spain.. Rev Esp Salud Publica 2013; 87: 25-33. doi: 10.4321/S1135-57272013000100004.

36. Asensio A, Di Bella S, Lo Vecchio A, et al. The impact of Clostridium difficile infection on resource use and costs in hospitals in Spain and Italy: a matched cohort study. Int J Infect Dis 2015; 36: 31-38. doi: 10.1016/j.jijid.2015.05.013.

37. Debast SB, Bauer MP, Kuijper EJ, et al. European Society of Clinical Microbiology and Infectious Diseases: update of the treatment guidance document for Clostridium difficile infection. Clin Microbiol Infect 2014; 20 Suppl 2: 1-26. doi: 10.1111/1469-0691.12418.

38. Ministerio de Sanidad Consumo y Bienestar Social. Registro de Altas - CMBD estatal. Manual de definiciones y glosario de términos., https://pestadistico.inteligenciadegestion.mscbs.es/publicoSNS/Comun/DescargaDocumento.aspx?ldNodo=6415 (2019).

39. Charlson ME, Pompei P, Ales KL, et al. A new method of classifying prognostic comorbidity in longitudinal studies: development and validation. J Chronic Dis 1987; 40: 373-83. doi: 0021-9681/87.

40. Quan $H_{1}$ S Sundararajan $V_{1}$ Halfon $P$, et al. Coding algorithms for defining comorbidities in ICD-9-CM and ICD-10 administrative data. Med Care 2005; 43: 1130-9. doi: 10.1016/j.aquaculture.2009.07.004.

41. Gisbert R, Brosa M. Healthcare cost database eSALUD. Oblikue Consulting, SL, http://www.oblikue.com/en/index.htm (2019, ac- 
cessed July 1, 2019)

42. Consejo General de Colegios Oficiales de Farmacéuticos. Bot PLUS 2.0, https://botplusweb.portalfarma.com (2013, accessed July 1, 2019).

43. Efron B, Tibshirani RJ. An Introduction to the Bootstrap. Chapman \& Hall/CRC, 1994.

44. Efron B. Better Bootstrap Confidence Intervals. J Am Stat Assoc 1987; 82: 171-185. doi: 10.1080/01621459.1987.10478410.

45. Parsons LS. Reducing bias in a propensity score Matched-pair Sample using greedy matching techniques. Proc 26th Annu SAS Users Gr Int Conf 2001; 214-226. doi: 10.1016/j.micinf.2011.07.011.Innate.

46. Yang D, Dalton J. A unified approach to measuring the effect size between two groups using SAS ${ }^{\circledR}$. SAS Glob Forum 2012; 6 .

47. R Core Team. R: A Language and Environment for Statistical Computing. Vienna, Austria, 2018.

48. Le Monnier A, Duburcq A, Zahar J-R, et al. Hospital cost of Clostridium difficile infection including the contribution of recurrences in French acute-care hospitals. J Hosp Infect 2015; 91: 117-122. doi: 10.1016/j.jhin.2015.06.017.

49. Tresman R, Goldenberg SD. Healthcare resource use and attributable cost of Clostridium difficile infection: a micro-costing analysis comparing first and recurrent episodes. J Antimicrob Chemother 2018; 73: 2851-2855. doi: 10.1093/jac/dky250.

50. Wilcox MH, Ahir $\mathrm{H}_{1}$ Coia JE, et al. Impact of recurrent Clostridium difficile infection: hospitalization and patient quality of life. J Antimicrob Chemother 2017; 72: 2647-2656. doi: 10.1093/jac/dkx174.

51. Hübner $\mathrm{C}$, Hübner N-0, Muhr M, et al. Cost analysis of hospitalized Clostridium difficile-associated diarrhea (CDAD). GMS Hyg Infect Control 2015; 10: Doc13. doi: 10.3205/dgkh000256.

52. Ryan $P$, Skally $M$, Duffy $F$, et al. Evaluation of fixed and variable hospital costs due to Clostridium difficile infection: institutional incentives and directions for future research. J Hosp Infect 2017; 95: 415-420. doi: 10.1016/j.jhin.2017.01.016.

53. Ghantoji SS, Sail K, Lairson DR, et al. Economic healthcare costs of Clostridium difficile infection: a systematic review. J Hosp Infect 2010; 74: 309-18. doi: 10.1016/j.jhin.2009.10.016. 